\title{
CREACIÓN, DISOLUCIÓN Y PARCELACIÓN DEL SEÑORÍO ALFONSINO DE DAYA VIEJA
}

\author{
Antonio Gil Olcina \\ Gregorio Canales Martínez
}

\begin{abstract}
RESUMEN
El fuero denominado alfonsino fue restablecido, el año 1772, por el gobierno de Carlos III como instrumento de colonización y reforma agraria en el reino de Valencia.

Daya Vieja, humedal bonificado en el Bajo Segura, antigua dehesa vinculada, adquirió condición de lugar alfonsino en 1791, vísperas ya de la disolución del régimen señorial. Al producirse ésta, su forma de explotación, es decir, el arrendamiento a corto plazo, permitió la pervivencia total y absoluta del elemento territorial y su inscripción, sin dificultad ni limitación alguna, en el registro de la propiedad.

Transmitida monolíticamente por sucesión hereditaria, la hacienda, que ocupaba íntegro el municipio de Daya Vieja y desbordaba sobre el de San Fulgencio, no se parceló, tras su enajenación global por el duque de Pinohermoso, hasta el segundo cuarto de este siglo.
\end{abstract}

\section{RÉSUMÉ}

Le privilège ("fuero") appelle "alfonsino" fut rétabli en 1772 par le gouvernement de Carlos III comme instrument de colonisation et de réforme agraire dans le Royaume de Valence.

Daya Vieja, marécage bonifié dans le "Bajo Segura", un ancien terrain "amayorazgado"(*), acquit la condition de lieu "alfonsino" en 1791, juste avant de la dissolution du Régime Seigneurial. A partir de ce moment, le mode d'exploitation -c'est-a-dire, l'affermage à court terme- permit au territoire une survie totale et complète, ainsi que son inscription dans le Registre de la Propriété sans aucune difficulté ni limitation.

La propriété foncière, qui représentait la totalité de la commune de Daya Vieja et une partie de celle de San Fulgencio, fut transmise d'un seul bloc et ne fut pas morcelée, après son aliénation globale faite par le Duc de Pinohermoso, jusqu'au deuxième quart de notre siècle.

$\left(^{*}\right)$ Constituant un majorat. 
Radicado íntegramente en la llanura aluvial del Bajo Segura, a la izquierda del río, el territorio de Daya Vieja es una pequeña porción del antiguo Sinus Illicitanus, rellenado paulatinamente, no sin cierto retraso a causa de la propia subsidencia y de la construcción de embalses, por los arrastres del Segura, Vinalopó y barrancos aledaños. Este medio físico plantea inconvenientes y ofrece posibilidades al aprovechamiento del suelo, la explotación de éstas y la superación de aquéllas integran un duro y prolongado proceso colonizador, que conjuga saneamiento e irrigación. Combinación ésta plasmada en la doble circulación de aguas, vivas y muertas, característica de la comarca.

Tal y como indican las Ordenanzas para el gobierno y distribución de las aguas que riegan la Huerta de la Ciudad de Orihuela y otros pueblos sujetos al juzgado privativo de la $m i s m a^{1}$, en dicho regadío el nombre de acequia se ha reservado tradicionalmente y guarda para las acequias madres o mayores, que toman directamente sus caudales del río Segura o reciclan los de azarbes; de ellas se alimentan las acequias menores o arrobas y de éstas los brazales, sangrados a su vez por las hijuelas. Esta red de riego se completa con otra de avenamiento o aguas muertas, que recibe "las espurgaciones, amarguras y salobres de las tierras"; su organización y estructura es inversa a la que posee la trama de aguas vivas, puesto que el proceso no es de reparto sino de adición. Por ello, el drenaje se inicia con los acueductos de menor débito o escorredores, a partir de los cuales se nutren sucesivamente azarbetas o azarbes menores y azarbes mayores. Estos últimos desaguan en el propio Segura, en otros azarbes más caudalosos o en acequias.

No constituyó, como se deja ver, tarea fácil la expansión del regadío en el espacio considerado, máxime si se tiene en cuenta la bonificación de áreas palustres y húmedas.

\section{Avenamiento e irrigación}

Daya Vieja, al igual que el resto del Bajo Segura, pertenece a la región climática del Sureste Peninsular, cuyo rasgo esencial es una acusada aridez. Se trata de un clima seco y soleado, definido básicamente por precipitaciones escasas (Orihuela, $317 \mathrm{~mm}$.; Guardamar, 287 mm.) e irregulares, acentuada sequía estival, débil nubosidad, fuerte predominio de cielos despejados, muchas horas de sol (casi 3.000 anuales), pocos días con precipitaciones (30-40), inviernos muy suaves, veranos calurosos, cuantiosa evapotranspiración potencial $(900 \mathrm{~mm}$.) y elevado déficit hídrico.

Dado el acusado grado de irregularidad, la precipitación media anual enmascara la existencia de años con totales ínfimos, a veces sucesivos, con largas y durísimas sequías. En abierto y flagrante contraste con éstas, esporádicamente se producen lluvias de gran intensidad, que en apenas unas horas rebasan y hasta duplican dicho promedio, causando monstruosas avenidas y devastadoras inundaciones. Períodos secos prolongados y copiosos aguaceros ocasionales son, en suma, manifestaciones paroxismales de un régimen pluviométrico extremadamente irregular. Bajo este condicionamiento climático, la transformación en regadío viene suscitada, en primer término, por la necesidad de asegurar la cosecha, sin desconocer que implica, además, un aumento de rendimientos unitarios y la posibilidad de nuevos cultivos.

Esta distinción básica entre el alto riesgo agrícola del secano semiárido y la relativa seguridad que depara el regadío constituye el punto de partida imprescindible para compren-

1 Ordenanzas para el gobierno y distribución de las aguas que riegan la Huerta de la Ciudad de Orihuela y otros pueblos sujetos al Juzgado Privativo de la misma. Orihuela, Impta. Zerón, 1946, pp. 8-10. 


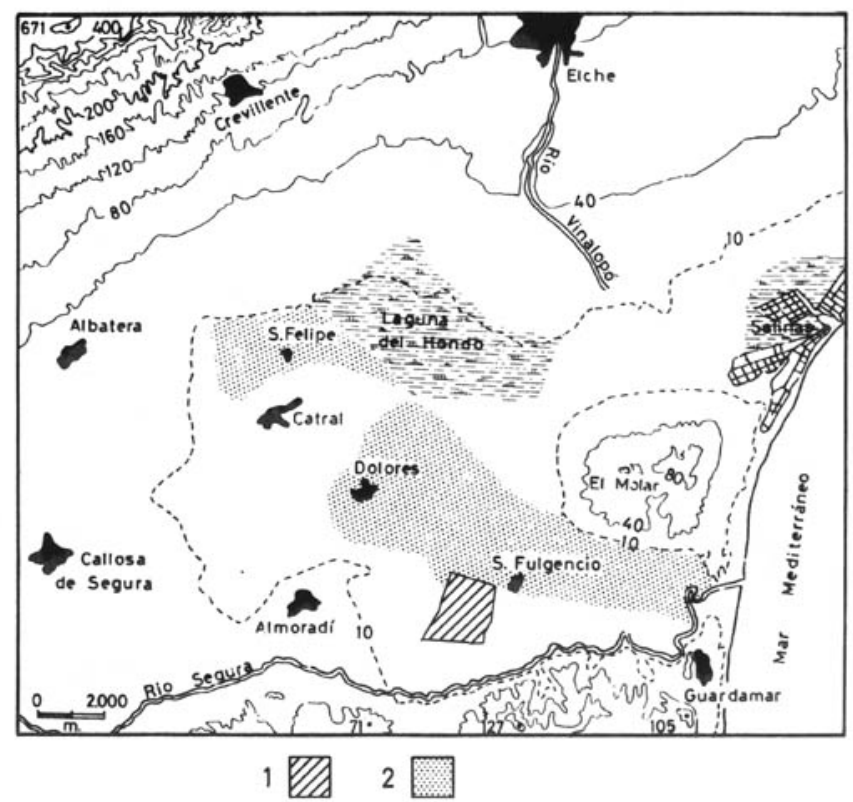

FIGURA 1: La bonificación de la mayor parte de la heredad de Daya Vieja se produjo simultáneamente y en estrecha relación con la de las Pías Fundaciones del cardenal Belluga, mediante convenio suscrito entre el titular de la primera y los comisionados de las segundas: 1) Término de Daya Vieja; 2) Pías Fundaciones o Villas Eximidas.

der el vasto empeño colonizador del Bajo Segura, al que se adscribe plenamente la ocupación y reducción a cultivo de la extensa heredad, señorío luego, de Daya Vieja.

La bonificación de dicha gran propiedad comenzó por su mitad meridional, que planteaba menos dificultades de desagüe y quedaba más próxima al Segura para recibir el agua de riego. Muy posterior, al menos dos siglos, es la colonización del resto, ligada a la excavación del sistema de azarbes en el coto limítrofe de las Pías Fundaciones, al que vierten los colectores de la tupida red de escorredores y azarbetas que drenan esta porción septentrional de Daya Vieja; ejes de la misma son los azarbes de Menargues e Higueras, procedentes del este y oeste respectivamente, cuya confluencia en ángulo recto con el azarbe Nanón, que viene del sur, da origen al azarbe del Marco, que, con rumbo norte, finaliza, en la llamada Casa del Marco, por una boca de 34 centímetros de diámetro labrada en piedra, a través de la cual sus aguas atraviesan, por una conducción subterránea, el azarbe de la Reina o Recibidor y continúan, 
en disposición normal a dicho merancho, hasta el azarbe mayor de la Culebrina ${ }^{2}$. Resulta tan esencial y notoria la trama de drenaje que el propio término, a excepción de su lindero oriental, que sigue un camino, queda encuadrado por el azarbe de Olivares, al sur, los de las Cruces y de la Reina, por el oeste, y el del Señor al norte.

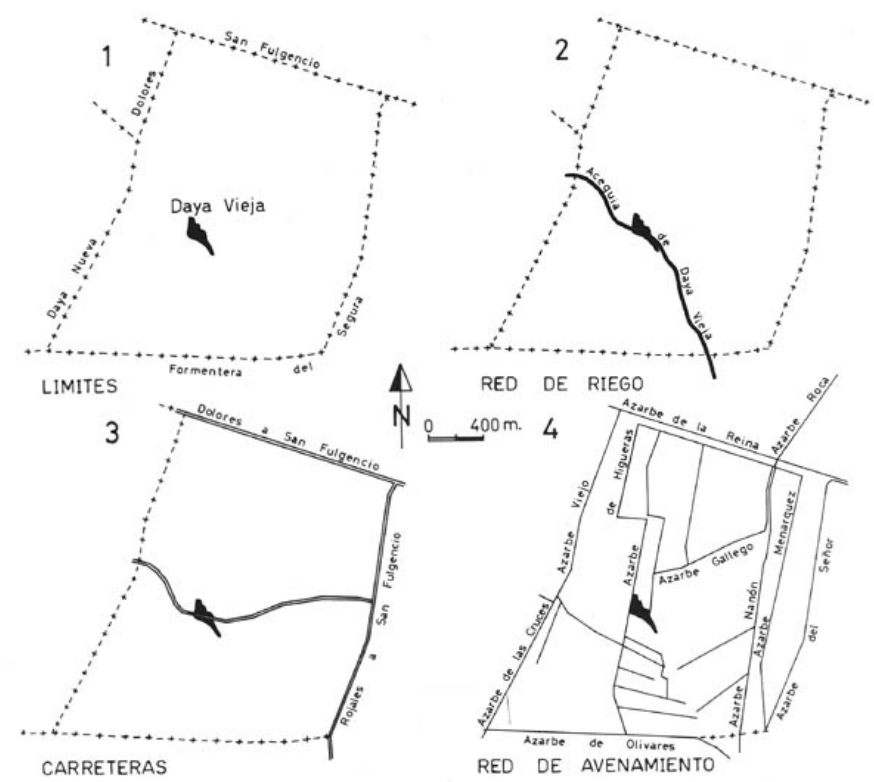

FIGURA 2: Término municipal de Daya Vieja: 1) El término de Daya Vieja, segregado en 1791 de Daya Nueva, lindaba por entonces con esta baronía, el señorío alfonsino de Formentera y las Villas Eximidas de Nuestra Señora de los Dolores y San Fulgencio. 2) Daya Vieja forma parte de la huerta de Orihuela y recibe riego a través de la Acequia Mayor de Daya Vieja, que arranca del Azud de Rojales. 3) Azarbes y caminos delimitan el término de Daya Vieja. 4) Sistema de escorredores, azarbetas y azarbes que avenan las tierras de Daya Vieja. Dicha red enlaza con el sistema de desagüe de las Pías Fundaciones.

El vertido de las aguas muertas de Daya Vieja en los azarbes de las Pías Fundaciones fue consecuencia de un convenio nacido del interés de éstas en eliminar un área limítrofe de

2 Datos facilitados por don José Lorenzo García, celador del Sindicato de Aguas de Daya Vieja, a quien hacemos patente nuestra gratitud. 
paludismo y utilizar sus aguas muertas, mientras el dueño de aquella heredad tenía, por añadidura, el objetivo primordial de reducir a cultivo todas sus tierras. Por ello figuró, entre las condiciones impuestas por el presbítero Don Juan Roca y Rocamora en la transmisión y cesión de la mencionada hacienda a su hermano Don Jerónimo, la de suscribir una concordia con la Junta de las Pías Fundaciones para el desagüe de los almarjales y carrizales de Daya Vieja. Dicho acuerdo quedó formalizado mediante escritura pública otorgada en Murcia, el 6 de agosto de 1738, por el expresado Don Jerónimo Roca y Rocamora y, de otra parte, el Canónigo Dr. Don Francisco Manzanilla, el Racionero Entero Don Juan de Molina y el Racionerio Medio Don Antonio de Mesa, éstos tres últimos Prebendados de la Santa Iglesia de Cartagena y Comisarios de la Junta de Fundaciones Pías establecidas por el Excmo. Sr. Cardenal Belluga. En este instrumento notarial consta el detalle de las obras a ejecutar para el avenamiento de Daya Vieja y otras complementarias encaminadas a obviar cualquier incidencia negativa en el Coto de las Pías Fundaciones, así como el compromiso asumido por Don Jerónimo Roca y Rocamora, por sí y sus sucesores, de no dar salida a otras aguas muertas que las procedentes única y exclusivamente de Daya Vieja, y la obligación adicional de satisfacer "por el día del Señor S. Juan de Junio veinte pesos de a quince rs. de vellón cada uno para la monda de los azarbes de la Culebrina y En medio, pertenecientes ambos a las Villas Eximidas"3.

Aguas arriba del azud de Rojales, sobre el Segura, parte por la margen izquierda, en término de Formentera, la Acequia de Daya Vieja, cuya boquera es, según Roca de Togores, de "9 palmos, 9 dedos de alto, con 2 palmos, 4 1 1/2 dedos de ancho, y por ella recibe del río 38 1/2 hilas de agua que aprovechan 2.605 tahullas en las huertas de Daya Vieja y de Formentera, con tanda intermedia de diez días: en la primera lo verifican 4 hilas y varias paradas en 2.511 tahullas, y en la segunda 4 zuas con las 94 restantes. Corre esta acequia unos 3 cuartos de legua, yendo á desaguar al azarbe viejo de Almoradí, y sitio intitulado el hoyo de la Cabeza"4. De dicha Acequia toman sucesivamente y reparten el agua a todo el término las acequias menores o arrobas, brazales e hijuelas.

Todos los contratos de arrendamiento de la heredad de Daya Vieja, anteriores incluso a 1738 , conceden especial atención a las cuestiones de riego y avenamiento, reguladas con detalle y minucia. Así, por ejemplo, en el otorgado por el presbítero Don Juan Roca y Rocamora, el 15 de noviembre de 1726, figuran, al comienzo, las dos condiciones siguientes: "Lo primero que dichos ..... Arrendatarios an de tener obligación de cultivar las tierras de dicha Heredad segun costumbre de buen labrador, pagar Diezmos y primicia a la Iglesia y todas las mondas de Aguas vivas y muertas de todos los edificios que al presente ay y en adelante hubiere en las tierras de dicha Heredad" y, a continuación, se reitera, en el capítulo segundo, que "dichos Arrendatarios a su costa an de mantener la Acequia que toma agua del Río de Segura de la qual se rriegan las tierras de dicha Heredad, así en la anchura que debe tener para el combeniente riego de dichas tierras, y dexarla así en el ultimo año de este Arrendamiento, y durante el sacar todos los ribazos y quigeros que se caieren en el buque de dicha Acequia, todo ello a su costa, y rebaxarlos estos si les pareciere a dichos Arrendatarios a su propia costa en el caso de acer la dicha rebaxa de ribazos y quigeros"5.

3 Acta de protocolización de testimonio literal referente a desagües de San Fulgencio. Notaría de D. José Fernández Ventura, 22 de agosto de 1968, Dolores. C1272160.

4 ROCA DE TOGORES, J.: Memoria sobre los riegos de la Huerta de Orihuela. Valencia, R.S.E.C.R.V., 1832, pp. 51-52.

5 "Escritura de Arrendamiento de la Heredad llamada la Daya Vieja, 15 de noviembre de 1726". Protocolo notarial de Bautista Ramón, 1726. Archivo Histórico de Orihuela (A.H.O.), Sig. 1.264, ff. 618 v. y 619. 
Transcurrido casi medio siglo, en 1783, con ocasión del arrendamiento de una de las haciendas de Daya Vieja, su propietario, el Muy Ilustre Señor Don Luis Roca Rossell Rocamora y Moncada, dueño del Lugar de Benejúzar, impone, en la segunda cláusula, que "dicho Arrendador tenga obligación de mondar las Ilas, Regaderas, escorredores y Azarvetas de aguas muertas pertenecientes a la referida Hacienda y contribuir con los demas Arrendatarios de las otras Heredades del enunciado territorio de dicha Daya Vieja a proporcion de las tahullas que cada uno tenga a la monta y repuntas de la Acequia propia de la expresada Daya Vieja de donde tienen todas el riego, como también a la monda de todos los Azarves y edificios Comunes, assi de aguas vivas como de muertas ....". Se trata, en definitiva, de una atención proporcionada a la importancia capital que para toda la Huerta de Orihuela posee el doble sistema circulatorio ${ }^{7}$.

\section{Contratos de locación y conducción}

La forma jurídica de explotación de Daya Vieja fue, al menos tres siglos, desde comienzos del XVII, el arrendamiento a corto plazo, con duraciones máxima de ocho años y mínima de cuatro. Dado que la bonificación de la mayor parte de la heredad se produjo de manera sincrónica y estrechamente ligada a la del coto de las Pías Fundaciones, sorprende que no se recurriera, como en éstas, al censo enfitéutico para el saneamiento de los humedales, como hizo también por entonces el duque de Arcos y marqués de Elche en los carrizales de Bassa Llarguera ${ }^{8}$. El desuso del establiment y la falta de arrendamientos superiores a ocho años inducen a sospechar, sin menosprecio de motivos económicos, la posibilidad de que ambas exclusiones puedan obedecer a restricciones legales resultantes del vínculo que sobre dicha hacienda y otros bienes fundó, a finales del XVII, Frey Pedro Dávalos Roca y Rocamora, Gran Castellán de Amposta, religioso profeso en la Orden de San Juan?

Con anterioridad al avenamiento de la totalidad de Daya Vieja, la superficie cultivada era objeto de un solo arrendamiento, a tanto alzado, distribuido en dos pagos, uno por Navidad y otro, ya cosechados los cereales, en San Juan de Junio. Los últimos años del seiscientos, iniciada ya la fase de expansión económica, crecimiento demográfico y demanda creciente de tierra cultivable, aumenta el rento y se añaden adehalas, tal y como muestra el cuadro I.

Es de notar que el canon sube un $43 \%$ entre dos contratos sucesivos, los de 1696 y 1703 , y casi se duplica en el intervalo de treinta años, al pasar de 350 a 650 libras, con período para este último rento de ocho años forzosos. Se trata invariablemente de arrendamientos a riesgo y ventura, sin que el conductor pueda pretender rebaja del precio convenido por causa alguna, es decir, "por ningún caso que suceda de esterilidad, havenidas del Rio, piedra, niebla, fuego,

6 "Escritura de Arrendamiento de la Heredad de tierra huerta titulada la Caseta del territorio de la Daya vieja, 17 de marzo de 1783”. Protocolo notarial de Juan Ramón Rufete. 1783, A.H.O., Sig. 1.579, f. 113.

7 GIL OLCINA, A. y CANALES MARTÍNEZ, G.: Residuos de propiedad señorial en España. Perduración y ocaso en el Bajo Segura. Alicante, Inst. Juan Gil-Albert, 1988, pp. 28-30.

8 ALTAMIRA Y CREVEA, R.: Derecho consuetudinario y economía popular de la provincia de Alicante, 1905. Edición facsímil, Alicante, Inst. J. Gil-Albert,1985, pp. 96-123.

9 “Escritura de Zezion y traspaso de la Heredad nombrada de la Daya Vieja, 4 de agosto de 1738". Protocolo notarial de Bautista Ramón, 1738, A.H.O., Sig. 1.276, f. 362. 
Cuadro I

ARRENDAMIENTOS DE DAYA VIEJA

\begin{tabular}{|c|c|c|c|c|c|}
\hline AŃo & ARRENDAMIENTO & VECINO DE & $\begin{array}{l}\text { CANON } \\
\text { (LIBRAS) }\end{array}$ & OTRAS CARGAS & DURACIÓN \\
\hline $1660^{10}$ & José Jerez & Rojales & 250 & & 4 años forzosos y 2 años voluntarios \\
\hline $1672^{11}$ & Antonio Rodríguez Valenciano & Guardamar & 300 & & 4 años \\
\hline $1690^{12}$ & Diego Gómez & Guardamar & 300 & & 8 años \\
\hline $1696^{13}$ & Francisco Martínez Espinosa & Orihuela & 350 & $\begin{array}{l}6 \text { libras año/reparo edificios o } \\
\text { red de riego. }\end{array}$ & 4 años forzosos y 4 años voluntarios \\
\hline $1703^{14}$ & Francisco Martínez Espinosa & Orihuela & 500 & $\begin{array}{l}\text { Un cerdo (valor } 10 \text { libras), } \\
\text { dos cahíces de arroz cáscara } \\
\text { una docena de gallinas. }\end{array}$ & 4 años forzosos y 2 años voluntarios \\
\hline $1720^{15}$ & Antonio Martínez Espinosa & Orihuela & 500 & $\begin{array}{l}\text { Dos cahíces de arroz en cebada } \\
\text { y una docena de gallinas. }\end{array}$ & 6 años \\
\hline $1726^{16}$ & Francisco González Navarrete & Orihuela & 650 & $\begin{array}{l}\text { Un cerdo (valor } 10 \text { libras), un } \\
\text { cahíz de arroz y doce gallinas. }\end{array}$ & 8 años \\
\hline
\end{tabular}

10 "Escritura de Arrendamiento de la Heredad de Daya Vieja, 8 de diciembre de 1660". Protocolo notarial de Roig Bartolome, 1660. A.H.O., Sig. 947, s.f.

11 "Escritura de Arrendamiento de la Heredad de Daya Vieja, 7 de julio de 1672". Protocolo notarial de Roig Bartolome, 1672. A.H.O. Sig. 959, s.f.

12 "Escritura de Arrendamiento de la Heredad de Daya Vieja, 13 de diciembre de 1690". Protocolo notarial de Martínez Llor, 1687-1690. A.H.O.., Sig. 1.140, ff. 96 a 100v.

13 "Escritura de Arrendamiento de la Heredad de Daya Vieja, 8 de febrero de 1969". Protocolo notarial de Martínez Llor, 1694-1696. A.H.O.., Sig. 1.142, ff. 3 a 8v.

14 "Escritura de Arrendamiento de la Heredad de Daya Vieja, 23 de junio de 1703". Protocolo notarial de Bautista Ramón, 1703. A.H.O., Sig. 1.244, ff. 230 a 235.

15 "Escritura de Arrendamiento de la Heredad de Daya Vieja, 5 de agosto de 1720". Protocolo notarial de Bautista Ramón 1703. A.H.O., Sig. 1.258, ff. 182-183.

16 "Escritura de Arrendamiento de la Heredad de Daya Vieja, 15 de noviembre de 1726". Protocolo notarial de Bautista Ramón 1726. A.H.O., Sig. 1.264, ff. 618 a 622. 
peste, guerras, langosta, pocas o muchas aguas, ni por otro ningún caso que suceda, pensado o impensado porque le arrienda dicha heredad a todo riesgo, peligro y aventura y con todos los que previene el derecho y la Ley" "17.

Las escrituras arrendaticias del XVII atribuyen a Daya Vieja una extensión total de novecientas tahullas (106,65 ha.), de las cuales 380 eran tierra campa y veinte de moreral, mientras el resto permanecía inculto. Por su parte, el contrato suscrito en 1726 describe la gran propiedad citada como "una Heredad de tierra blanca con su Casa y Abitaziones que ay en ella nombrada dicha Heredad La daia Vieja con todo el numero de tahullas labradisas de riego e incultas de que se compone ..." ${ }^{\prime 18}$. De todo ello se infiere que el aprovechamiento primordial consistía en la cerealicultura, que añadía a los cereales de invierno, con destacada primacía del trigo, el arrozal, mal se entendería, si no, la inclusión entre las adehalas de arroz en sebada (arroz cáscara) y arroz blanco (molido); es de recordar que el cultivo del arroz fue prohibido en 1403 y dicha disposición conservó vigencia durante tres siglos y medio, hasta 1753, aunque menudearon, empero, las excepciones a favor de la nobleza terrateniente. Sin embargo, éstas no estuvieron libres de altibajos; así, en 1738 el presbítero Don Juan Roca y Rocamora, dueño de Daya Vieja hubo de condonar al arrendatario de la misma una importante suma, entre otros motivos, a causa de los perjuicios que se le habían seguido al mismo por "no haver podido sembrar, ni plantar Arroses en las tierras de dicha Heredad de los expresados dos años de setezientos treinta y quatro, y treinta y cinco, ni logrado sus cosechas, siendo de la mayor estimación, por estar prohivida la siembra de dichos Arrozes en esta Ciudad y pueblos circumvezinos por Real Decreto de Su Mag. que se mandó publicar y publicó..."19. Recordemos asimismo que la condición $10^{\text {a }}$ del establecimiento enfitéutico de las Pías Fundaciones, aprobado por Real Cédula de 13 de mayo de 1745, ordenaba no sembrar porción alguna de arroz "con ningun titulo, causa, razon ni motivo", al haberlo decretado así el Rey en atención a "lo nocivo a la salud pública que es este esquilmo".

El interés de los dueños de Daya Vieja en ampliar la superficie cultivada se hace patente en una cláusula del tenor siguiente: "Que todas las tierras incultas de dicha Heredad que los dichos Arrendatarios icieren de cultivo, se entienden comprehendidas en este Arrendamiento, y todas las que se aplicasen a las de las que se entienden comprehendidas en las dadas al eminentísimo Cardenal Belluga, en el caso de declararse por de dicha Heredad y aplicarse a ella. Y por el mayor util que por ellas tuvieren dichos Arrendatarios estos no devan pagar mas cantidad de Arrendamiento que la que se expresa en esta escritura" 20 , aunque asimismo se hace constar que al arrendatario no le asistía derecho alguno, concluido el contrato, al abono de mejoras.

Resuelto el desagüe y propagado el riego, el área cultivada en Daya Vieja se quintuplicó y, con ello, desapareció el arrendamiento único y global. Los contratos del nuevo período son más completos y minuciosos; figuran con mayor detalle las obligaciones de los colonos sobre riegos y avenamientos, al tiempo que se regulan las labores de escarda, traílla y número de rejas. Aparece la imposición de arborizar, habitualmente con olivos, una determinada

17 Escritura de Arrendamiento de la Heredad de Daya Vieja, 5 de agosto de 1720”. Protocolo notarial de Bautista Ramón, 1720. A.H.O., Sig. 1.258, ff. 183.

18 "Escritura de Arrendamiento de la Heredad de Dava Vicia, 15 de noviembre de 1726”. Protocolo notarial de Bautista Ramón, 1726. A.H.O., Sig. 1.264, ff. 618.

19 “Transacción y Concordia entre partes de Franco González Navarrete de una y de la otra Don Juan Roca y Rocamora Presbítero". Protocolo notarial de Bautista Ramón, 1738. A.H.O.. Sig. 1.276, Escritura de 12 de mayo de 1738 , f. 181.

20 Escritura cit. nota 18. f. 619. 
Cuadro II

ARRENDAMIENTO DE LAS OCHO HEREDADES QUE COMPONIAN LA HEREDAD DE DAYA VIEJA . AÑO 1783

\begin{tabular}{|c|c|c|c|c|c|c|}
\hline ARRENDATARIO ${ }^{21}$ & $\begin{array}{l}\text { VECINO } \\
\text { DE }\end{array}$ & HACIENDA & $\begin{array}{c}\text { SUPERFICIE } \\
(\mathrm{HA})\end{array}$ & $\begin{array}{c}\text { RENTA } \\
\text { LIBRAS-SUELDOS }\end{array}$ & $\begin{array}{l}\text { OBLIGACIÓN } \\
\text { DE PLANTAR }\end{array}$ & DURACIÓN \\
\hline Manuel Mora & Rojales & Del Marco & 28,20 & $637-15$ & 2,37 Ha de olivar & 6 años \\
\hline Tomás García de Félix & Benejúzar & Era Alta & 32,23 & 413-19 & “ & 6 años \\
\hline $\begin{array}{l}\text { P. Fajardo Sánchez y } \\
\text { José García de Félix }\end{array}$ & Benejúzar & Casa Grande & 41,95 & 583 & “ & 6 años \\
\hline $\begin{array}{l}\text { Esteban Gómez y } \\
\text { Andrés Félix }\end{array}$ & Benejúzar & De Olma & 35,43 & $460-5$ & “ & 6 años \\
\hline $\begin{array}{l}\text { I. García Hurtado y } \\
\text { José García de Seva }\end{array}$ & Rojales & Del Centro & 33,77 & $458-16$ & " & 6 años \\
\hline $\begin{array}{l}\text { Antonio Gil } \\
\text { Ginés Martínez y }\end{array}$ & Daya Nueva & La Caseta & 47,40 & 600 & " & 6 años \\
\hline José Martínez & Benejúzar & Azarbe Vieja & 45,62 & $591-15$ & " & 6 años \\
\hline José Ribera & Rojales & Del Rincón & 35,78 & $497-10$ & “ & 6 años \\
\hline
\end{tabular}

21 Fuente: Protocolo notarial de Juan Ramón Rufete, 1973. A.H.O., Sig. 1579, Escrituras de 26 de febrero, 17 de marzo y 23 de abril de 1783 (ff. 61-83, 112-116 y 174-182) 
superficie, sin otra aportación del propietario que los plantones. Además de las cláusulas tradicionales, las referidas a los aspectos citados se encuentran, por ejemplo, en los ocho pactos formalizados el año 1783, cuyo resumen básico contiene el cuadro II.

La mayoría de los arrendatarios proceden de Benejúzar, señorío de jurisdicción baronal perteneciente al propio dueño de Daya Vieja, Don Luis Roca Rossell Rocamora y Moncada, cuyos apellidos evidencian las prácticas endogámicas de la nobleza oriolana.

En 1783, de las 300,38 hectáreas cultivadas, 273,26 eran de tierra blanca y primordial dedicación cerealista, 15,99 con cultivo asociado de viña y olivo, 3,32 exclusivamente de olivar y 7,81 de moreral. Unos años después, en 1795, Cavanilles da como principales cosechas del que ya era señorío alfonsino de Daya Vieja, con 19 vecinos, las producciones siguientes: 1.000 cahíces de trigo, 80 de cebada y 50 de maíz, 500 arrobas de hortalizas, 400 de cáñamo y 100 de 1 lino ${ }^{22}$. Como esquimo principal continúan los cereales, con marcada primacía del trigo, aunque sobresale asimismo el avance de las plantas textiles, en especial el cáñamo, bien adaptado a estos regadíos. Sorprende la ausencia de toda mención del arbolado, en especial del olivo, cuya plantación se convirtió en norma obligada para los arrendatarios.

Incorporadas las jurisdicciones por el decreto de 6 de agosto de 1811, Daya Vieja, que perdió la condición de señorío alfonsino alcanzada en 1791, mantuvo, en cambio, la condición de lugar obtenido en esta última fecha. De todo ello hay claro reflejo en el contrato de 1828, donde, a excepción de un arrendatario de San Fulgencio, término sobre el que desbordaba la heredad de Daya Vieja, los restantes viven en este lugar; es de destacar también que las haciendas arrendadas son 14, número que obviamente guarda estrecha relación con el mínimo de 15 hogares indispensable para el logro de la jurisdicción. Tampoco es mera casualidad el tamaño similar de las fincas, con superficies que varían entre límites de 20 y 23 hectáreas, tal y como pone de manifiesto el cuadro III.

Cuadro III

ARRENDAMIENTO DE LAS HACIENDAS DE DAYA VIEJA POR JUAN NEPOMU CENO ROCA Y CARRASCO, SEÑOR DE BENEJÚZAR. AÑO 1828.

\begin{tabular}{llllll}
\hline NOMBRE DEL ARRENDATARIO $^{23}$ & VECINO DE & HACIENDA & SUPERFICIE HA & CANON & \multirow{2}{*}{ DURACIÓN } \\
\hline José García Velasco & Daya Vieja & Casa Grande & 20,9123 & 54 cahíces de trigo & 4 años \\
José García Velasco & Daya Vieja & Casa Nueva & 21,7417 & 50 cahíces de trigo & 4 años \\
Francisco García Mirete & Daya Vieja & La Veleta & 22,7488 & 55 cahíces de trigo & 4 años \\
Juan Martínez Sánchez & Daya Vieja & Azarbe Nueva & 20,0237 & 29 cahíces de trigo & 4 años \\
Ginés Martínez García & Daya Vieja & Del Rincón & 21,4455 & 40 cahíces de trigo & 4 años \\
José López Mora & Daya Vieja & El Plantel & 20,0829 & 37 cahíces de trigo & 4 años \\
Manuel García Velasco & Daya Vieja & La Olma & 20,8531 & 52 cahíces de trigo & 4 años \\
Fermín Blasco Aracil & Daya Vieja & Del Marco & 20,8531 & 51 cahíces de trigo & 4 años \\
Ginés Martínez Campos & Daya Vieja & La Cortera & 21,4455 & 35 cahíces de trigo & 4 años \\
Pedro López & Daya Vieja & Hera Alta & 22,0972 & 40 cahíces de trigo & 4 años \\
Joaquín López Hernández & Daya Vieja & Del Centro & 22,0379 & 45 cahíces de trigo & 4 años \\
Teodoro Martínez Campo & Daya Vieja & La Caseta & 21,5640 & 46 cahíces de trigo & 4 años \\
Cayetano y José Martínez García & Daya Vieja & Azarbe Vieja & 22,0379 & 34 cahíces de trigo & 4 años \\
Manuel Villena & San Fulgencio La Caseta & 21,6825 & 37 cahíces de trigo & 4 años \\
\hline & & & 299,5261 & 605 cahíces de trigo & \\
\hline
\end{tabular}

22 CAVANILlES, A. J.: Observaciones sobre la Historia Natural. Geografia, Agricultura. Población y frutos del Reyno de Valencia. Madrid, Impta. Real, 1795-1797 (Reed. facsímil, Gráficas Soler, Valencia, 1972), II, p. 283.

23 Fuente: Protocolo notarial de Pedro Turón, 1828. A.H.O., Sig. 1.966, Escrituras de 14 de agosto, 25 de agosto, 28 de agosto, 29 de agosto, 23 de septiembre, 15 de octubre, 31 de octubre y 13 de diciembre de 1828), ff. 435-453, 464-468, 480-484, 491-502, 566-571, 636-648, 765-985 y 1.007-1.103. 
Como se aprecia, el canon se paga ahora en especie, en trigo, advirtiendo que éste ha de ser "claro, colado y espolsado del mejor que se coge en la referida heredad medido con barchilla de boca ancha", y se prohíbe que el arrendatario "pueda regar los trigos a tiempo de granar, y si lo hiciere, no se le admitirá el que dé de esta clase .... ni tampoco se le admitirá trigo que sea de la primera parva" 24 . Menudean las indicaciones sobre abonos, forrajes y cultivos; entre éstos, aparte del trigo, se mantiene crecido interés por los olivares, en los que el colono tan sólo podrá "sembrar panizo, proiviendole el restoblar las tierras de la expresada heredad, y solo podra hacerlo en las ondas ..... el año que saliese el Río y entrare en ellas, exceptuando el ultimo de este arriendo que las dejara amedianadas, como también las altas, deviendo tragillar estas, y escardar en tiempo oportuno para evitar que se aomillen las tierras" ${ }^{25}$; en 1828, la tierra campa, con 264,33 hectáreas, cubría el $88,3 \%$ de la cultivada, mientras el resto era olivar y ocupaba 35,19 hectáreas. Muestra del interés por la cosecha de seda es la obligación que contrae el arrendatario de entregar, concluido el contrato, una barraca de seis andanas con dos puertas a beneficio de su Escelencia ... ${ }^{26}$. Diversos capítulos abordan aspectos tan esenciales como el mantenimiento de la red de aguas muertas, conservación de la acequia de Daya Vieja, sus brazales e hijuelas, estancamiento del agua para riego y reparación de las motas rotas por las crecidas del Segura.

Mediado el XIX, Madoz señala que el terreno de Daya Vieja es "llano, sumamente fértil como el de toda la Huerta de Orihuela: comprende unas 2.000 tahullas, propias del señor territorial, y se riega con las aguas del río Segura ...”, y cita como sus producciones más importantes las de trigo, maíz, aceite, vino, cáñamo, legumbres y hortalizas ${ }^{27}$.

Logro de la jurisdicción alfonsina, abolición de la misma y pervivencia del señorío solariego En 1738 el presbítero Don Juan Roca y Rocamora transfirió a su hermano Don Gerónimo Roca de Togores y Rocamora la Heredad de Daya Vieja, parte integrante del vínculo que fundara, a finales del XVII, frey Pedro Dávalos Maza y Rocamora, Gran Castellán de Amposta. Dicha propiedad había sido legada, en virtud de testamento otorgado en 1582, por Doña Violante Soler y Rajadel, fallecida sin sucesión, a su sobrino Juan Roca de Togores y Togores, VI Señor de las Cañadas y Baronías de Ruidoms, que se tituló asimismo Señor de la Daya ${ }^{28}$. Conviene, empero, advertir que Daya Vieja era un señorío de jurisdicción ínfima o, más bien, una simple dehesa, cuyo rasgo distintivo de la mera hacienda privada consistía en que, por hallarse deslindada y amojonada, sus hierbas o pastos quedaban, libres de sujeción comunal, a la entera disposición del propietario ${ }^{29}$. Casi cuatro lustros antes que su transformación en lugar alfonsino la dotase de término propio, una de las cláusulas del arrendamiento de 1783 previene que dicho Arrendatario, (sic), no pueda tener Ganado de ninguna especie

24 “Arrendamiento Dn. Josef Die Lloren a favor de José García Blasco”. Protocolo notarial de Pedro Turón,1828. A.H.O. Escritura de 14 de agosto de 1828, (f. 436).

25 Escritura cit. nota 24, f. 437.

26 Escritura cit. nota 24, f. 437 v.

27 MADOZ, P.: Diccionario Geográfico-Estadístico de España y sus posesiones de Ultramar. Madrid, 1847,VII, p. 364.

28 FINESTRAT, barón de: Nobiliario alicantino. Alicante, Inst. Est. Alicantinos, 1983, pp. 245-246.

29 GIL OLCINA y CANALES MARTÍNEZ, Op. cit.. p. 27. 


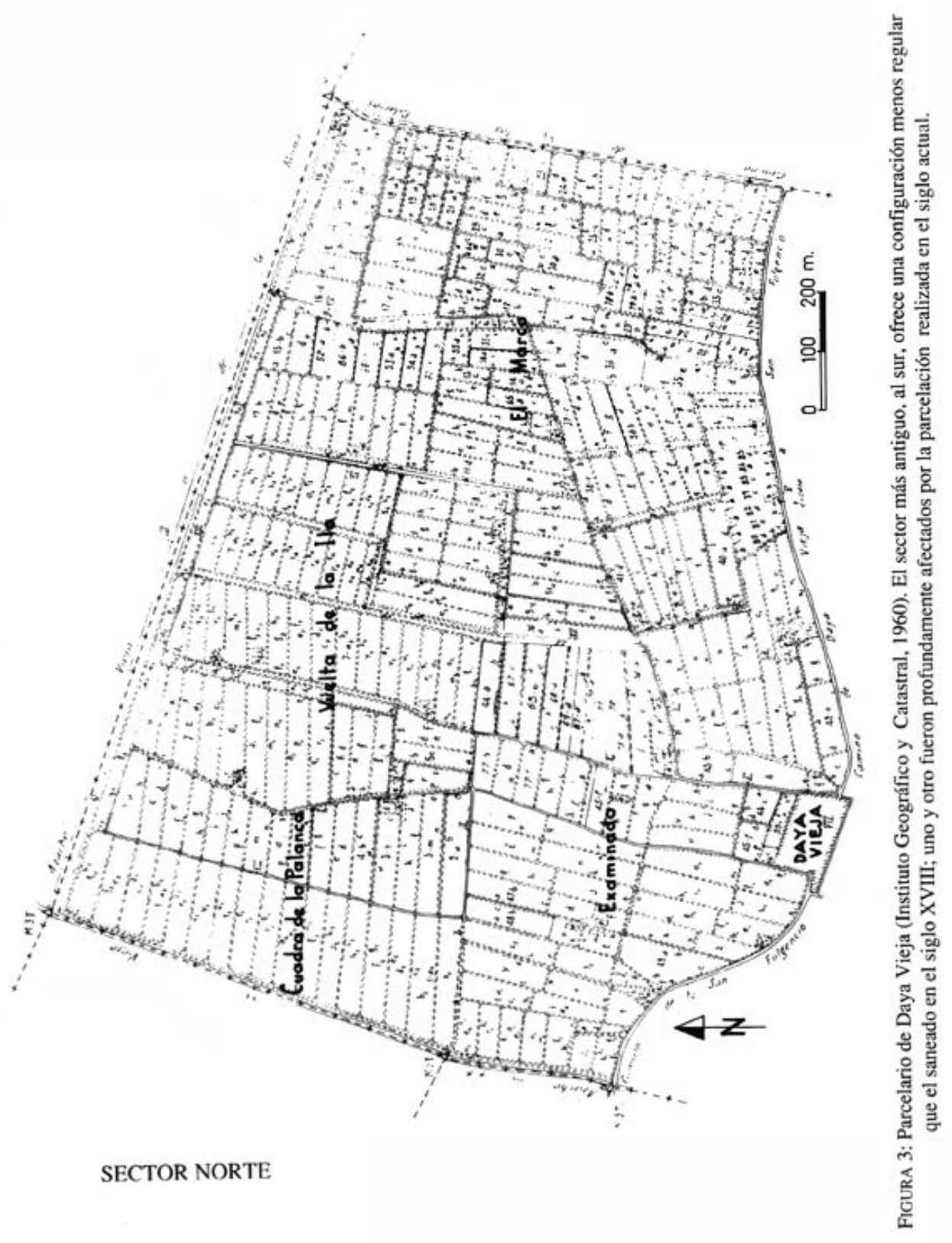




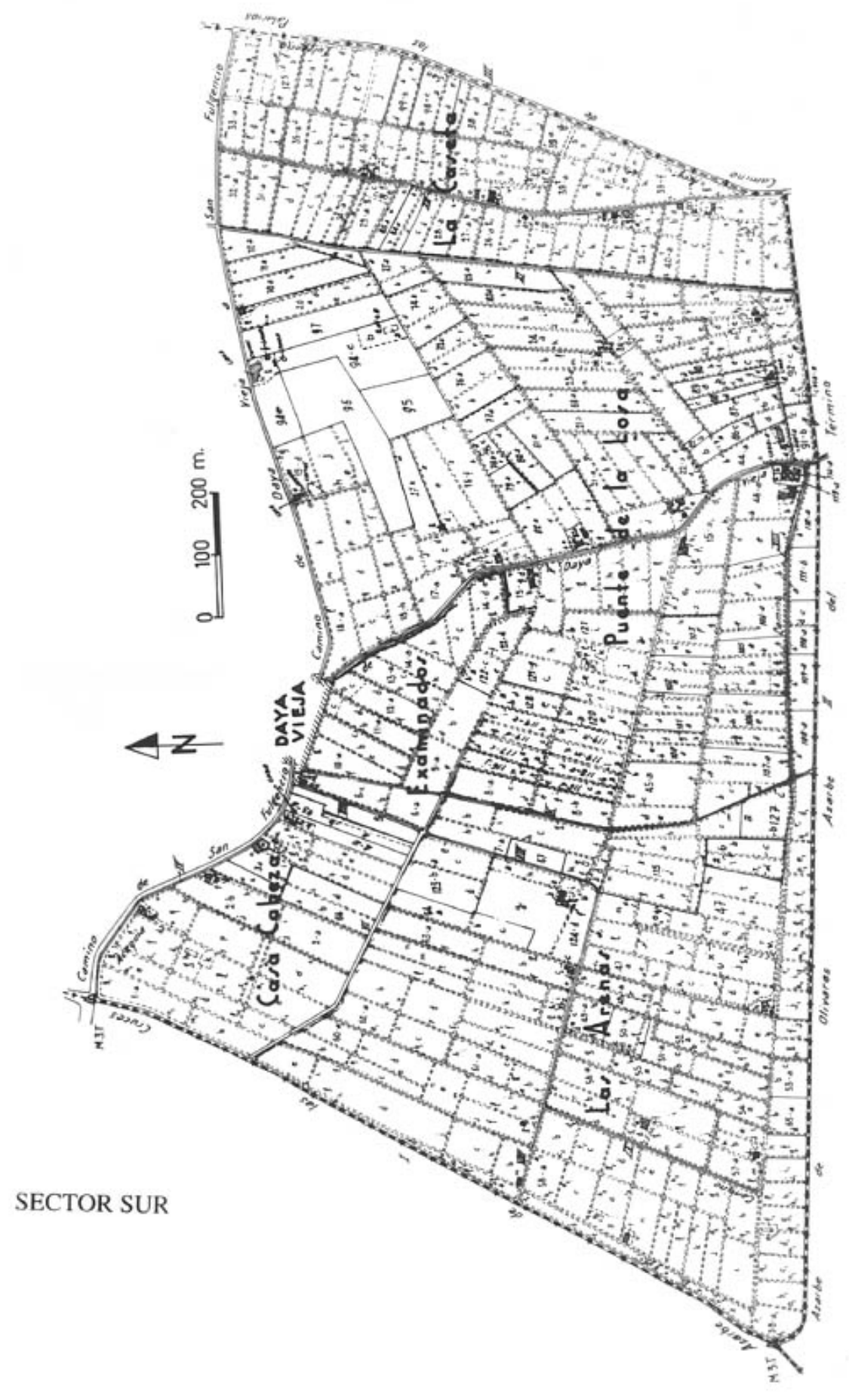


para pastar las yervas de la expresada Hazienda, porque siendo propias del señor otorgante, se las reserva para utilizarlas como le parezca ${ }^{30}$.

Casi veinte años después de la Real Provisión de 16 de mayo de 1772, por la que Carlos III restablecía el llamado fuero alfonsino en el reino de Valencia ${ }^{31}$, el Real Acuerdo declaraba, por providencia de 18 de julio de 1791, "en favor del Conde de Pinohermoso y sus sucesores la Jurisdicción Alfonsina en el Lugar llamado la Daya Vieja fundado en el termino del de la Daya nueva, para que la exerzan entre sus havitantes y termino por medio de los Alcaldes y Oficiales que nombren, y se mandaron señalar y amojonar para el efecto todas las tierras cultas, e incultas pertenecientes al expresado Conde, con citación de los Pueblos del contorno, y que en estos terminos deve tenerse por Lugar enteramente separado y comunicarsele a su Justicia las Ordenes correspondientes, como otro de los Pueblos de este Partido, en el modo y forma que se comunican a los demás" 32 .

No es del caso detenerse en las circunstancias que acompañaron la reposición de este fuero $^{33}$, derogado como el resto de los Furs por el Real Decreto de 29 de junio de 1707, tan sólo subrayar que reaparecía, bajo el gobierno de Carlos III, como instrumento de colonización interior $\mathrm{y}$, hasta cierto punto, reforma agraria.

Cumplidas las dos exigencias precisas por Don Juan Nepomuceno Mariano Roca de Togores y Escorcia, I Conde de Pinohermoso, el fuero alfonsino hizo de Daya Vieja un nuevo lugar. Con referencia a este tipo de causas, una Noticia del Fuero Alphonsino, curioso documento posterior a 1785, sin fecha ni pie de imprenta, posiblemente originado en una Sociedad Económica, con la declarada finalidad de mover "a que los demás Reynos de España supliquen á S.M. la extensión de esta Gracia, que en nada se opone á las Leyes, y Privilegios de los Reynos ${ }^{34}$, recuerda que el Fuero solo pide dos circunstancias, la primera construir las quince Casas: La segunda poblarlas de Christianos Casados. Purificadas las condiciones, por el ministerio de la Ley, se adquiere la Jurisdicción perpetuamente ..... siempre el Real Acuerdo conoce, y Posesiona a los Fundadores de los Lugares, por tratarse de una Ley hecha en Cortes; de un contrato mutuo, citroque obligatorio; de un contrato oneroso; de un contrato de buena fe, fiado en la Palabra Real; de una Declaración Real de la Ley; de la utilidad pública de la Población, y demas utilidades ....".

Hagamos hincapié en que el logro de la jurisdicción no implicaba, en modo alguno, el establiment; y nada tiene de extraño que, cuando, salvo raras excepciones, la enfiteusis había perdido todo su atractivo, el conde de Pinohermoso no recurriese a la división de dominios para poblar Daya Vieja. Mantuvo el régimen de arrendamiento a corto plazo, que permitía la revisión e incremento del canon y evitaba la adquisición de cualquier tipo de derecho, al término del contrato, por parte del arrendatario o sus derechohabientes sobre la hacienda temporalmente cedida. Convertida en lugar, Daya Vieja no dejó de ser una gran propiedad agrícola, con el aditamento de que su dueño ejercía la jurisdicción alfonsina y disfrutaba de

30 "Arrendamiento de la Heredad de tierra huerta titulada Caseta del territorio de la Daya vieja, 17 de marzo de 1783", Protocolo notarial de Juan Ramón Rufete, 1783. A.H.O., Sig. 1.579, f. 113 v.

31 GIL OLCINA, A.: "La propiedad de la tierra en los señoríos de jurisdicción alfonsina", Investigaciones Geográficas, 1 (1983), pp. 7-24.

32 Carta acordada manifestando que, por providencia de este Real Acuerdo de 18 de julio del año próximo pasado (1791), se declaró en favor del Conde de Pinohermoso y sus sucesores la Jurisdicción Alfonsina en el lugar llamado la Daya vieja. Archivo Municipal de Orihuela, armario 21, leja $\mathrm{n}^{\mathrm{o}} 4$, legajo 2.102, s.f.

33 GIL OLCINA, A.: “Jurisdicción alfonsina y poblamiento valenciano”, Cuadernos de Geografia,1986, núms. 39-40, pp. 241-245.

34 Noticia del Fuero Alphonsino. 
los derechos exclusivos, privativos y prohibitivos, si bien, por el reducido vecindario, éstos se contraían a la almazara, donde los colonos venían obligados a molturar la cosecha de oliva. La exigencia de quince hogares, como mínimo, para obtener la jurisdicción alfonsina, originó un embrión de pueblo, puso, como en tantos otros puntos del reino de Valencia, el fundamento de un futuro municipio y multiplicó el número de explotaciones, pero no dividió la propiedad, que, gracias al régimen de tenencia adoptado, permaneció intacta y plena en manos de la Casa de Pinohermoso. Además, el modo de explotación escogido no llevaba implícitas capacidades de parcelación y poblamiento similares a las del censo enfitéutico; en estrecha relación con ello, los terrazgos de Daya Vieja resultaban de extensión media muy superiores a los de otros lugares alfonsinos enfiteuticados, no existía dispersión parcelaria y el crecimiento demográfico fue lento, frenado por la limitada cifra de fincas y viviendas;

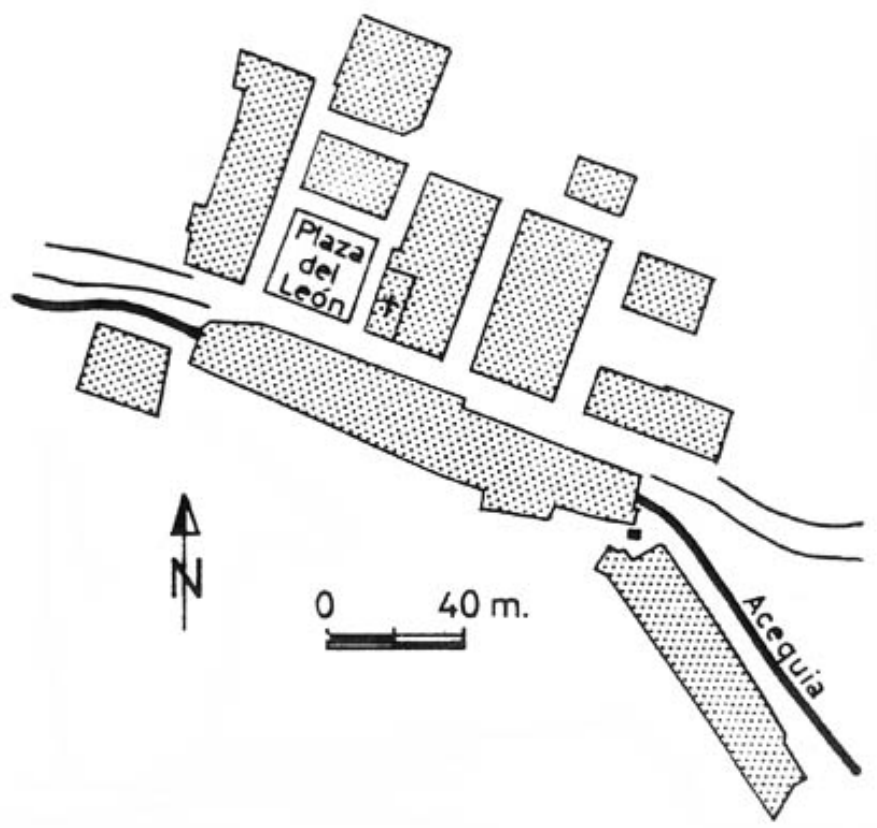

FIGURA 4: El callejero, escasamente desarrollado, corresponde a un núcleo de nueva planta levantado en el último cuarto del XVIII y parcialmente reconstruido tras el terremoto de 1829. En el limite meridional se aprecia el emplazamiento del caserío sobre la mota, menos expuesta a las inundaciones del Segura (1988). 
Cavanilles cuenta 19 vecinos $^{35}$, Madoz anota que Daya Vieja "tiene 11 casas que forman una calle y una plaza, cárcel reducida y una ermita"36, el censo de 1857 registra 76 habitantes, que eran 212 para 1900 y 359 veinte años después.

A diferencia del establiment, el arrendamiento a corto plazo, al producirse la incorporación de jurisdicciones, salvaguardó íntegramente y sin dificultad alguna el señorío territorial de Daya Vieja. Tan distintas fueron las consecuencias de uno y otro régimen de tenencia que, sin consideración formal de regalía, el conde Pinohermoso conservó el monopolio de la almazara, incluido en los arrendamientos de 1828 como una cláusula más, del tenor siguiente: "Que el nominado arrendatario tenga obligación de hacer toda la oliva que se cogiere en la citada heredad en la almazara que existe en dicho pueblo propia de su Excelencia"37.

Por supuesto, no se planteó dificultad alguna para inscribir en el Registro de la Propiedad de Dolores el municipio de Daya Vieja como finca propiedad del conde de Pinohermoso, en estos términos: "Hacienda situada en el termino del pueblo de dicho nombre y una pequeña parte en el de San Fulgencio, con 299 Ha., 64 a. y 05 ca., con riego de la acequia propia que toma el agua del río Segura por el azud de Rojales. En la hacienda hay un grupo de nueve casas para labradores, una principal para el dueño y tres más enclavadas en distintas partes de la hacienda, con almazara, bodega, cuadras, pajeras, ermita....".38.

Todavía en 1919, el Avance Catastral de la Provincia de Alicante registraba para Daya Vieja un único propietario, que no era otro sino el duque de Pinohermoso. Aún transcurrirían algunos años antes de que, a raíz de su enajenación por el citado título, la estructura agraria del municipio experimentase una intensa mutación.

\section{Compraventa y parcelación de Daya Vieja}

Dato muy significativo de la importante acumulación de bienes raíces en la Casa de Pinohermoso es que la relación de mayores contribuyentes por inmuebles, cultivos y ganadería de 1875 situase al conde de esa denominación primero en las provincias de Albacete y Alicante y destacado en la de Murcia, correspondiéndole el lugar decimotercero en el conjunto nacional, con una cuota de 47.653,12 pesetas $^{39}$. Fallecido en 1884 sin sucesión Don Juan Nepomuceno Roca de Togores y Carrasco, dejó por herederos a sus familiares más próximos. Integraban su fortuna bienes libres y de obligada asignación; estos últimos consistentes en la mitad de los adscritos a los suprimidos mayorazgos que disfrutó el extinto, correspondían por imperativo legal a su sobrina Enriqueta Roca de Togores y Conrradini, condesa de Velle.

De los bienes de origen libre o que habían adquirido dicha condición por mor de las disposiciones desvinculadoras, ordenó algunas mandas y pensiones, legó los procedentes de la herencia materna en Orihuela a su sobrino Luis Roca de Togores y Roca de Togores, conde de Luna, y con el resto hizo tres partes, dos en favor de su hermano Mariano Roca de Togores y Carrasco, marqués de Molins, y la tercera de por mitad para la mencionada Enriqueta Roca de Togores y los derechohabientes de la marquesa de Beniel, hermana del testador.

35 CAVANILLES, Op. cit., II, ( p. 292).

36 MADOZ, Op. cit., VII, p. 364.

37 “Arrendamiento Don Josef Die Lloren a favor de José García Blasco, 14 de agosto de 1828”, Protocolo notarial de Pedro Turón, 1828. A.H.O., Sig. 1.966, f. 438.

38 Fuente: Libro de Inscripciones de las Dayas, libro I. Registro de la Propiedad de Dolores.

39 CONGOST I COLOMER, R.: “Los mayores contribuyentes y la desamortización”, Desamortización y Hacienda Pública, 1986, II, pp. 629-652. 
Obviamente el artículo $2^{\circ}$ de la Ley de Supresión de Mayorazgos de 27 de septiembre de 1820 limitó la disgregación de las antiguas vinculaciones al reservar su mitad, que, además, en este caso cuando fue de libre disposición, encontró dos generaciones de heredero único. A consecuencia de la citada norma, la nueva condesa, luego duquesa de Pinohermoso, recibió la mayor parte del patrimonio de la Casa, en cuantía estimada el año 1884 de 1.381 .082 pesetas.

Heredó después dicha fortuna territorial el hijo de la duquesa, Manuel Pérez Seoane y Roca de Togores, cuya hijela ascendió a 3.114.196 pesetas según la escritura de ratificación y aprobación de operaciones particionales efectuada en Madrid el 18 de junio de 1927. En pago del expresado haber se le adjudicó, con otras muchas fincas, la hacienda de Daya Vieja, que poco después, mediante compraventa otorgada en Madrid el 18 de diciembre de 1928, vendió a los hermanos José García Palmer y Monserrate García Castillo, industriales vecinos de Murcia, al precio de 1.500 .000 pesetas; el valor asignado a Daya Vieja en la referida escritura particional había sido de 700.000 pesetas.

Como se ha indicado, el coto redondo de Daya Vieja abarcaba una superficie de 299,6405 hectáreas, ocupaba por entero dicho término municipal y desbordaba ligeramente sobre el de San Fulgencio. Al momento de formalizar el contrato los compradores desembolsaron 3.500 pesetas en pago de la parcela de San Fulgencio y otras 296.500 a cuenta del importe de Daya Vieja. La cantidad restante de 1.200.000 pesetas se fraccionó en ocho pagos; de ellos, uno de 200.000 pesetas en 15 de abril de 1929 y los siete restantes, con cantidades que oscilaban de 190.000 a 90.000 pesetas, vencían el 15 de diciembre de los años 1929 a 1935; la cantidad pendiente de amortización redituaba el 6 por ciento anual. Se estipuló igualmente que la falta de pago en la fecha convenida o de los intereses a su debido tiempo daba derecho al vendedor a tener por vencidos todos los demás plazos y reclamar cuanto se le adeudara.

Todo hace pensar que los compradores proyectaron y realizaron un excelente negocio de parcelación y venta de terrenos, prueba de ello son los datos del Cuadro IV.

Del indudable éxito de la operación convence que el producto de los precios confesados en las escrituras correspondientes a las 75 parcelas, con una superficie total de 201,41 hectáreas, enajenadas entre 1929 y 1933 subió a 1.342 .261 pesetas.

Tras el paréntesis impuesto por la guerra civil, las ventas se reanudaron en el período 1941-49, año éste a partir del cual se transfirieron esporádicamente los últimos restos salvo alguna finca de considerable extensión. Interesa destacar que la parcelación fue intensa y casi generalizada. Baste señalar que de los 61 adquirientes cuarenta y uno $(67,2 \%)$ lo fueron de menos de 5 hectáreas, mientras sólo cuatro compraron por encima de 10 y únicamente tres se hicieron con más de 20 hectáreas; recordemos que este máximo era, en cambio, el módulo usual de las explotaciones arrendadas en el segundo cuarto del XIX. La clasificación de los compradores de tierras en Daya Vieja, atendidas las superficies escrituradas, figura en el cuadro $\mathrm{V}$.

Asimismo las dimensiones de los lotes definen un tipo de parcelación orientada a encontrar abundante clientela entre la multitud de arrendatarios, terrajeros y hasta jornaleros del Bajo Segura. De un total de 125 lotes, nada menos que 115 (92\%) comprendían superficies por bajo de cinco hectáreas y de ellos 79 eran inferiores a dos hectáreas, con la distribución expresada en el cuadro VI.

Los compradores, catalogados en su mayoría como labradores y jornaleros, proceden en su casi totalidad de municipios de la Vega Baja, si bien su vecindad, lejos de circunscribirse a Daya Vieja, revela una operación de ámbito comarcano. Los detalles de profesión y origen se ponen de manifiesto en los cuadros VII y VIII respectivamente.

Intacta en manos del linaje que la había poseído por espacio de casi tres siglos y medio, la heredad de Daya Vieja, transformada en lugar y municipio, ha concluido, tardíamente y 
Cuadro IV

VENTA DE TIERRAS Y CASAS DE LA HEREDAD "DAYA VIEJA"

\begin{tabular}{|c|c|c|c|c|c|c|c|c|c|}
\hline AÑo & $\begin{array}{r}\text { SUPERFICIE } \\
\text { VENDIDA (HA) }\end{array}$ & $\%$ & $\begin{array}{r}\text { SUPERFICIE } \\
\text { SOLARES }\left(M^{*}\right)\end{array}$ & $\%$ & $\begin{array}{r}\text { N. }{ }^{e} \text { LOTES } \\
\text { TIERRA } \\
\end{array}$ & $\%$ & $\begin{array}{l}\text { N., LOTES } \\
\text { SOLARES } \\
\end{array}$ & $\%$ & $\begin{array}{r}\text { VALOR } \\
\text { PTAS. } \\
\end{array}$ \\
\hline 1929 & 102,9189 & 34,6 & 71,6 & 0,9 & 35 & 28 & 1 & 4,3 & 654.372 \\
\hline 1930 & 23,1684 & 7,8 & - & - & 7 & 5,6 & - & - & 147.287 \\
\hline 1931 & 23,1684 & 7,9 & - & - & 5 & 4,0 & - & - & 173.505 \\
\hline 1932 & 22,2872 & 7,5 & - & - & 10 & 8,0 & - & - & 120.105 \\
\hline 1933 & 30,8703 & 10,4 & - & - & 18 & 14,4 & - & - & 216.992 \\
\hline 1936 & 1,1948 & 0,4 & - & - & 1 & 0,8 & - & - & 5.500 \\
\hline 1941 & 17,6569 & 5,9 & 319 & 4,2 & 12 & 9,6 & 1 & 4,3 & 74.000 \\
\hline 1944 & 12,0646 & 4,0 & 281,5 & 3,7 & 3 & 2,4 & 2 & 8,7 & 71.200 \\
\hline 1945 & 9,5482 & 3,2 & - & - & 5 & 4,0 & - & - & 32.000 \\
\hline 1949 & 10,3359 & 3,5 & - & - & 8 & 6,4 & - & - & 46.000 \\
\hline 1958 & 11,9979 & 4,0 & 997,95 & 13,1 & 8 & 6,4 & 4 & 17,4 & 201.680 \\
\hline 1962 & - & - & 409,0 & 5,4 & - & - & 3 & 13,1 & 1.400 \\
\hline 1965 & 28,7822 & 9,7 & 1.264 & 16,6 & 10 & 8,0 & 7 & 30,5 & 99.700 \\
\hline 1966 & 1,0980 & 0,4 & - & - & 1 & 0,8 & - & - & 6.000 \\
\hline 1967 & - & - & 4.153 & 54,6 & - & - & 4 & 17,4 & 37.000 \\
\hline 1977 & - & - & 112,2 & 1,5 & - & - & 1 & 4,3 & 20.000 \\
\hline \multirow[t]{2}{*}{1978} & 2,2205 & 0,7 & - & - & 2 & 1,6 & - & - & 125.000 \\
\hline & 297,8235 & 100,0 & $7.608,25$ & 100,0 & 125 & 100,0 & 23 & 100,0 & \\
\hline
\end{tabular}

Fuente: Registro de la Propiedad de Dolores. 
con vía distinta, por asemejarse, con un parcelario más geométrico y menos evolucionado, a las estructuras agrarias de sectores donde el censo enfitéutico acarreó, a través de la fragmentación del dominio útil y de su inscripción en los registros de la propiedad, el minifundismo y la dispersión parcelaria.

\begin{tabular}{ccccc}
\multicolumn{5}{c}{ Cuadro V } \\
\hline TAMAÑo (HA) & COMPRADORES & \multicolumn{1}{c}{$\%$} & SUPERFICIE (HA) & $\%$ \\
\hline$<0,49$ & 1 & 1,6 & 0,3616 & 0,1 \\
$0,50-0,99$ & 2 & 3,3 & 1,6476 & 0,6 \\
$1,00-1,49$ & 14 & 23,0 & 17,8612 & 6,0 \\
$1,50-1,99$ & 8 & 13,1 & 14,3564 & 4,8 \\
$2,00-2,49$ & 6 & 9,8 & 13,9486 & 4,7 \\
$2,50-2,99$ & 4 & 6,6 & 10,8468 & 3,6 \\
$3,00-3,99$ & 3 & 4,9 & 9,9521 & 3,3 \\
$4,00-4,99$ & 3 & 4,9 & 13,0430 & 4,4 \\
$5,00-5,99$ & 3 & 4,9 & 16,0947 & 5,4 \\
$6,00-6,99$ & 4 & 6,6 & 25,8901 & 8,7 \\
$7,00-7,99$ & 4 & 6,6 & 30,3112 & 10,2 \\
$8,00-8,99$ & 3 & 4,9 & 25,6445 & 8,6 \\
$9,00-9,99$ & 2 & 3,3 & 18,9629 & 6,4 \\
$10,00-19,99$ & 1 & 1,6 & 15,7548 & 5,3 \\
$20,00-29,99$ & 2 & 3,3 & 51,3268 & 17,2 \\
$>30$ & 1 & 1,6 & 31,8212 & 10,7 \\
\hline
\end{tabular}

\begin{tabular}{ccccc}
\multicolumn{5}{c}{ Cuadro VI } \\
\hline TAMAÑo & $\mathrm{N}^{2}$ DE LOTES & $\%$ & SUPERFICIE $($ HA) & $\%$ \\
\hline$<0,24$ & 1 & 0,8 & 0,1778 & 0,1 \\
$0,25-0,49$ & 10 & 8,0 & 4,0609 & 1,4 \\
$0,50-0,74$ & 5 & 4,0 & 2,9306 & 1,0 \\
$0,75-0,99$ & 12 & 9,6 & 10,7646 & 3,6 \\
$1,00-1,49$ & 33 & 26,4 & 39,8391 & 13,4 \\
$1,50-1,99$ & 18 & 14,4 & 31,2399 & 10,5 \\
$2,00-2,49$ & 12 & 9,6 & 26,5800 & 8,9 \\
$2,50-2,99$ & 9 & 7,2 & 24,4276 & 8,2 \\
$3,00-3,99$ & 8 & 6,4 & 27,9012 & 9,4 \\
$4,00-4,99$ & 7 & 5,6 & 30,1607 & 10,1 \\
$5,00-5,99$ & 2 & 1,6 & 11,1397 & 3,7 \\
$6,00-6,99$ & 3 & 2,4 & 18,7924 & 6,3 \\
$7,00-8,99$ & 2 & 1,6 & 16,9167 & 5,6 \\
$9,00-14,99$ & 1 & 0,8 & 9,1283 & 3,1 \\
$>15$ & 2 & 1,6 & 43,7640 & 14,7 \\
\hline
\end{tabular}




\begin{tabular}{lcrrr}
\multicolumn{5}{c}{ Cuadro VII } \\
\hline ACTIVIDAD & COMPRADORES & $\%$ & SUPERFICIE (HA) & $\%$ \\
\hline Labrador & 19 & 31,1 & 101,6362 & 34,1 \\
Jornalero & 14 & 23,0 & 30,8293 & 10,4 \\
Sus labores & 7 & 11,5 & 51,9098 & 17,4 \\
Propietario & 4 & 6,6 & 25,0692 & 8,4 \\
Agricultor & 2 & 3,3 & 5,3790 & 1,8 \\
Comerciante & 2 & 3,3 & 40,0989 & 13,5 \\
Industrial & 1 & 1,6 & 15,7548 & 5,3 \\
No consta & 12 & 19,6 & 27,1463 & 9,1 \\
\hline & 61 & 100,0 & 297,8235 & 100,0 \\
\hline
\end{tabular}

Cuadro VIII

\begin{tabular}{lcrrr}
\hline MUNICIPIOS & COMPRADORES & $\%$ & SUPERFICIE (HA) & $\%$ \\
\hline Daya Vieja & 13 & 21,3 & 43,8673 & 14,7 \\
Formentera & 13 & 21,3 & 34,7017 & 11,6 \\
Rojales & 8 & 13,1 & 32,3313 & 10,9 \\
Almoradí & 8 & 13,1 & 101,2087 & 34,0 \\
Dolores & 6 & 9,8 & 14,2049 & 4,8 \\
Orihuela & 6 & 9,8 & 27,8919 & 9,4 \\
Benijófar & 2 & 3,3 & 4,3313 & 1,5 \\
Daya Nueva & 2 & 3,3 & 6,9667 & 2,3 \\
Murcia & 2 & 3,3 & 31,0327 & 10,4 \\
Bigastro & 1 & 1,7 & 1,2870 & 0,4 \\
\hline & 61 & 100,0 & 297,8235 & 100,0 \\
\hline
\end{tabular}

